\title{
Análise do aceite da Missão das Nações Unidas para a estabilização no Haiti pelo congresso brasileiro \\ Helvisney dos Reis Cardoso ${ }^{1}$
}

\section{Resumo}

A atuação em Missões de Paz da ONU, em concordância com os princípios da Política Externa brasileira, ganhou maior destaque nas discussões internas do Congresso Nacional. Por meio de uma análise dos documentos oficiais do governo brasileiro, busca-se mostrar a influência direta do caráter da missão - humanitária ou intervencionista - na aprovação junto ao Congresso Nacional, tendo como pressuposto que é interesse fixo do Poder Executivo que a aprovação ocorra. Ao final, demonstra-se que o posicionamento do Poder Legislativo brasileiro se dá em concordância com o histórico posicionamento do País em sua atuação internacional - respeito à não intervenção e soberania de outros Estados - priorizando sempre as causas humanitárias em detrimento da intervenção.

\section{Palavras-Chave}

Congresso; Processo decisório; Diplomacia presidencial; Haiti; Missões de Manutenção da Paz da ONU; Política externa brasileira.

\section{Abstract}

The participation in UN Peacekeeping Missions, in accordance with the Brazilian foreign policy principles drawn over the years, has gained greater importance in the National Congress internal discussions. Through an analysis of the official documents of the Brazilian government, we seek to show that the character of the mission humanitarian or interventionist - has direct influence on its approval by the National Congress, considering the assumption that the Executive Power interest for its approval is fixed. At the end, we demonstrate that the positioning of Brazilian Legislative Power takes place in accordance with the historical position of Brazil in its international activities - non-intervention and respect for the sovereignty of other States - always prioritizing humanitarian causes over intervention.

\section{Keywords}

Congress; Decision making process; Presidential Diplomacy; Haiti; United Nations Peacekeeping Missions; Brazilian foreign policy

\footnotetext{
${ }^{1}$ Graduado em Relações Internacionais pela Universidade de Brasília (2013.2) e, atualmente, mestrando em política internacional e comparada pela mesma universidade. Atua como assistente de projetos no Programa das Nações Unidas para o Desenvolvimento.
} 


\section{Introdução}

O presente trabalho tem por objetivo analisar o processo de aceite pelo Congresso Nacional do Brasil do envio de tropas para a Missão das Nações Unidas para a estabilização do Haiti (MINUSTAH). Pretende-se, por meio de um panorama da recente história do Haiti e da análise do processo decisório que levou o Brasil a integrar a Missão da Organização das Nações Unidas (ONU), tanto no âmbito do poder Executivo e do Legislativo, delinear algumas considerações a respeito da política externa brasileira.

Após séculos de ditaduras, lutas políticas e crise socioeconômica, a situação da primeira república negra das Américas (o Haiti) se agravou, em 2004, a partir da renúncia do presidente Jean-Bertrand Aristide. $\mathrm{O}$ caos generalizado e a iminência de uma guerra civil ensejaram a mobilização urgente da comunidade internacional. $O$ Conselho de Segurança das Nações Unidas (CSNU) estabeleceu uma Força Multinacional Interina (MIF), a fim de evitar a eclosão de uma guerra civil, enquanto estruturava uma operação de paz.

Atendendo ao chamado da ONU, o Brasil aceitou participar da Missão, com o envio de 1200 militares e assumiu seu comando militar. A decisão reflete características, princípios e objetivos da atual política externa brasileira. As justificativas e o próprio processo decisório, em caráter de diplomacia presidencial, são motivos de discussões em âmbito político, diplomático, acadêmico, militar e também pela mídia. De cunho material ou abstrato, as possíveis razões para a participação brasileira na MINUSTAH vão desde o multilateralismo e a busca por um assento permanente no CSNU, à nova principiologia da política externa brasileira, pautada na não indiferença, diplomacia solidária (AMORIM, 2007) e a forte diplomacia presidencial.

A pesquisa foi desenvolvida primordialmente sob uma abordagem dialéticoindutiva, utilizando como método uma análise histórica, a partir de fontes primárias e secundárias; resoluções do CSNU; diários da Câmara dos Deputados; matérias veiculadas pela imprensa e sítios eletrônicos oficiais de interesse.

Estrutura do processo decisório brasileiro relacionado ao aceite de Missões de Paz da ONU

Atualmente, uma decisão brasileira de enviar tropas para missões de paz envolve o Ministério das Relações Exteriores (MRE), o da Defesa (MD), o do Planejamento 
Orçamento e Gestão (MPOG), a Presidência da República e o Congresso Nacional (UZIEL, 2010).

Normalmente, quando ainda está em cogitação o estabelecimento ou expansão de uma operação, a ONU formula uma consulta informal à Missão brasileira em Nova Iorque que tece argumentos sobre a conveniência política da missão e as repassa ao MRE. Nessa fase, um diálogo com o MD é estabelecido a fim de averiguar, por exemplo, a disponibilidade de tropas, e com a Presidência para a verificação da viabilidade de participação da missão do ponto de vista político. Caso seja possível um acordo, é feita uma sinalização à ONU e um pedido formal é realizado.

Cabe ao Legislativo, por meio da Lei 2.593/1956 (REPÚBLICA FEDERATIVA DO BRASIL, 1956), aprovar por Decreto Legislativo, o envio de tropas e suas dimensões. Porém, a legislação em vigor não especifica essa tramitação que foi estabelecida na prática (UZIEL, 2010).

Para Uziel (2010), esse procedimento apresenta uma séria de dificuldades. Algumas delas são: (1) baixa institucionalidade, haja vista a não previsão em norma das etapas dispostas; (2) o Congresso não recebe informações sistemáticas sobre as missões empregadas; (3) a decisão acaba, assim, sendo morosa e dificultosa não atendendo as expectativas das Nações Unidas.

Em 1993, a Proposta de Lei 4380-A (REPÚBLICA FEDERATIVA DO BRASIL, 1994) propunha um Grupo de Trabalho Interministerial para a análise da viabilidade de apoio brasileiro a uma missão de paz da ONU. Seu sentido geral era delimitar mais claramente as competências dos diversos órgãos estatais e facultar ao executivo maior margem de manobra, tendo como objetivo acelerar o processo decisório (FONTOURA, 1999). Entretanto, a proposta modificando a legislação, e assim o processo decisório, não chegou a ser adotada.

\section{Arcabouço teórico sobre o papel do congresso}

Christopher Hill (2003) analiza como os Estados lidam com o seu ambiente externo. $\mathrm{O}$ autor observa a relação entre os fatores humanos e materiais que constituem o mundo e como os Estados se encontram numa rede de instituições, regras e expectativas que ajudam a formar as orientações da política externa.

O pensamento de Hill (2003) se enquadra dentro das teorias de interdepedência, globalização ou estruturalistas, que identificam uma moldura geral, ou um conjunto de 
forças, às quais as partes componentes (os Estados e outros atores internacioanis) estão subordinanas e são dependentes.

Algumas das fontes dessa interdepência, segundo Hill (2003), são: (1) a rede institucional de organizações internacionais. Juntos os Estados representam uma rede complexa e crescente que gera muitas trocas diplomáticas, além de também possibilitar $\mathrm{o}$ acesso às potencias menores ao poder de "agenda setting"2. (2) O direito internacional é melhor entendido como fonte de interdependência política do que um molde de governança. O direito internacional serve à função formal de estabelecer e delimitar a soberania dos Estados, tornando-os conscientes do sistema. Os Estados também precisam do direito internacional para conduzir transações, regular áreas específicas e proteger contra a interferência ilícita e estabelecer o princípio da reciprocidade. (3) As normas informais. Por normas entende-se: os princípios gerais que os Estados reconhecem em sua participação diária nas RIs. No processo de estabelecimento de normas, a publicidade e transparência são de importância vital. A opinião mundial é outro indicativo de confiança, que indica se as normas foram internalizadas. (4) Hierarquia dos Estados. É a percepção de sua posição relativa dependendo das circunstâncias. (5) As organizações não governamentais internacionais e outros processos transnacionais criam pontos de sensibilidade e vulnerabilidade política. Os tomadores de decisão estatais entendem as ONGs internacionais como parte inerente do ambiente ao qual eles têm que responder.

Dentro dessa perspectiva de interdependência, Mello e Silva (1998) identifica dois modelos iniciais de análise de política externa brasileira (PEB). O primeiro modelo é o da "nação incompleta", baseado no marxismo e na teoria da dependência. A teoria da dependência possui duas vertentes: (1) a determinista, cuja análise da política externa em si mesma não é importante, sendo resultado das convergências das elites da periferia e do centro; e (2) a não determinista, cuja dependência é condicionante da política externa e varia em função de fatores estruturais internos e externos (MELLO E SILVA, 1998).

O segundo modelo é o "baluarte do ocidente", baseado no realismo, e foca "nos conflitos estratégicos que moldam a estrutura do sistema internacional para, a partir dai,

\footnotetext{
${ }^{2}$ Agenda-setting pode ser definido como o poder de determinar a pauta de discussão dentro de uma organização ao destacar determinados temas e preterir, ofuscar, vetar ou ignorar outros tantos (TSEBELIS, 1994).
} 
derivar estratégias de ação diplomática fundadas na noção de uma aliança especial com os EUA" (MELLO E SILVA, 1998, p. 140).

Há ainda, segundo a autora, um terceiro modelo, que junta a visão realista com os conceitos de centro/periferia e de desenvolvimento econômico combinado e desigual, ambos da CEPAL. Esse modelo, diz Mello e Silva (1998), influenciou os tomadores de decisão em política externa no Brasil fortemente.

As análises de política externa no Brasil teriam ficado, então, focadas em fatores de natureza tangível: políticos, econômicos e estratégicos. Em tais análises, foca-se tanto no plano interno e suas disputas, quanto no grau de permissividade da anarquia internacional. $\mathrm{O}$ valor das ideias na tomada de decisão foi historicamente deixado de lado na academia brasileira voltada à PEB. Mello e Silva (1998) aponta, assim, dois paradigmas fortes na política externa brasileira: o americanista, surgido com Rio Branco, e o globalista, mais realista e nacionalista, surgido na década de 60 , e que universalizava a política externa. O poder passa a ser procurado por uma maior inserção global, buscando uma relação menos assimétrica com os EUA. Após um retorno ao americanismo nos primeiros governos militares, a partir dos anos 70 e até o final dos 80 há uma forte retomada ao globalismo. Ela aponta que tanto as questões internas quanto externas vividas pelo Brasil e o mundo, no início dos anos 90, começaram a questionar o modelo globalista, e lança uma pergunta se o que se seguiu não seria um novo modelo, combinando as duas tradições, que ela chamou, conforme parágrafo anterior, de terceiro modelo, baseado na CEPAL.

Mello e Silva (1998) aponta que ambos os paradigmas clássicos da PEB, globalista e americanista, incorporam um acervo diplomático permanente, ou seja, um conjunto de normas e posturas, pacifismo, não intervencionismo, defesa da igualdade soberana das nações, respeito ao Direito Internacional, que são percebidos como patrimônio histórico e estariam intrinsecamente associados ao comportamento internacional do País.

Não obstante, Maria Regina Soares de Lima (1994) busca assinalar a existência de paradigmas alternativos de política exterior na recente história do País, além de ressaltar a crise das "teorias históricas" de ação diplomática e o esgotamento de suas possibilidades. A autora reduz as diferentes perspectivas sobre política exterior a três enfoques básicos: o clássico, o político-social e o interativo. Para fins deste trabalho usaremos o enfoque interativo. 
Em seu enfoque interativo, Lima (1994) enfatiza as conexões da política externa com a política interna. Arcabouço teórico que foi formalizado por Robert Putnam (1988) com base no modelo dos jogos de dois níveis. O modelo de jogo de dois níveis argumenta que ações do Sistema Internacional impactam as tomadas de decisões no ambiente político doméstico, assim como as decisões políticas internas afetam fortemente o Sistema Internacional. O principal problema do Executivo seria, portanto, a busca de uma estratégia de negociação que seja politicamente viável nas ordens interna e externa (LIMA, 1994).

Por conseguinte, pode-se dizer que a interdependência dos Estados nacionais estimula formas variadas de regulação domésticas e internalizam-se questões internacionais, a política externa passa a regular de fato questões que faziam parte do ambiente regulatório doméstico. Assim sendo, a politização da política externa é inevitável (HIRST e LIMA, 2002).

Logo, uma análise sob a ótica da influência do congresso sob as relações exteriores do país se faz necessária. Ao contrário do que muitos pensam, a influência do Legislativo nos assuntos internacionais é profunda, sútil e benéfica. Não há contradição: se por um lado o Legislativo pode prejudicar a unidade perante uma negociação internacional e diminuir o poder de agência do Executivo, pois, por outro, ele confere credibilidade aos acordos firmados (MARTIN, 2000).

Credibilidade é o argumento básico para a defesa da participação do Legislativo nos assuntos externos e, mais precisamente, na Cooperação Internacional. O que ocorre é que como o Sistema Internacional é anárquico e nada, teoricamente, pode obrigar o Estado a cumprir os compromissos que vier a assumir, a credibilidade se torna a única garantia. As democracias têm grandes vantagens nesse sentido justamente devido à participação do Legislativo.

A credibilidade é uma solução para o problema da ação coletiva e pode diminuir os custos de transação na medida em que os Estados confiam uns nos outros para abrir mão de ganhos menores (porém garantidos) agora em nome de ganhos maiores no médio ou longo prazo. Credibilidade e cooperação estão intrinsecamente ligadas (MARTIN, 2000).

Os realistas acreditam que a cooperação só pode existir se o hegemon arcar com a tarefa de promovê-la (teoria da estabilidade hegemônica), já os institucionalistas acham que instituições internacionais podem suprir o papel do hegemon. Os dois lados, entretanto, desconsideram o fator doméstico e o que Lisa Martin faz é justamente incluir 
a ideia dos jogos de dois níveis nessa análise. Se o Sistema Internacional abre possibilidades para a cooperação, o ambiente doméstico é o que dá condições para o Estado se comprometer com acordos de cooperação ou não (MARTIN, 2000).

Há quem acredite que o Legislativo não tem interesse em política externa, mas isso não é verdade para muitos casos. Os políticos em geral têm interesse nos resultados de políticas, não importa se domésticas ou internacionais. O Legislativo não dispõe de meio mais efetivo de influenciar na política internacional do que por meio do Executivo ao trabalhar de forma conjunta. É repetidamente dito que a relação entre os dois poderes não é de disputa por espaço, mas sim de complementaridade e de intercâmbio de interesses (MARTIN, 2000). Mesmo que não seja aparente o Legislativo tem meios variados para influenciar o Executivo. Alguns deles são: (1) "purse power"; (2) delegação; e (3) controle.

Purse power diz respeito à capacidade do Poder Legislativo aprovar o orçamento e poder cortar gastos de órgãos ou agentes que contrariem suas posições sobre determinado tema. Além disso, qualquer compromisso assumido pelo Executivo no exterior que precise de verbas terá que passar pelo Legislativo. Isso faz com que o Executivo, antes de firmar compromissos, leve em conta a posição do Legislativo para não passar pelo constrangimento de não poder implementar o que foi acordado.

A segunda forma é por meio da delegação. O Legislativo ao delegar funções ao Executivo não está abrindo mão de seu poder, pelo contrário, está buscando um meio mais efetivo de ter seus objetivos alcançados. Primeiro porque o Legislativo já tem que lidar com uma infinidade de assuntos e, segundo, porque as questões internacionais exigem conhecimento especializado, o que o Executivo está mais apto a suprir. A delegação só ocorre quando há o reconhecimento de que as intenções do Executivo são condizentes com ao do Poder Legislativo. Uma decorrência disso é que governos com pouca base no parlamento geralmente tem dificuldade de conseguir a delegação.

Por fim, o controle pode ser definido pelo seu papel de "police patrol", uma supervisão constante e geral que acaba sendo pouco efetiva (devido à dificuldade de se fiscalizar tudo), e de "fire alarm", o Legislativo entra em cena quando tem algum interesse especial ou quando há algum indício de irregularidade (MARTIN, 2000).

Uma participação institucionalizada do Legislativo permite que se possa antecipar o seu posicionamento e evitar discordância entre o que o Executivo acorda e o que o 
Legislativo aceitaria. Isso acaba por diminuir o "win set"3 do negociador e aumentar seu poder de barganha numa negociação (como ocorre nos Estados Unidos da América).

Mesmo que o Legislativo não se disponha a conceder mais autonomia ao Executivo pela delegação, por exemplo, não significa que a sua participação nos compromissos afirmados seja inviável. Há mecanismos que podem ser utilizados para mitigar os problemas de ação coletiva dentro do parlamento. Por exemplo: partidos fortes que acabam disciplinando seus membros, levando a uma maior unidade de posições ou, ainda, a criação de comissões que funcionam como "gate keepers", agilizando o processo e direcionando as discussões (MARTIN, 2000).

Houve uma mudança na concepção de "Estado forte", antes se tratava de um Estado que tinha autonomia e liberdade para negociar, atualmente entende-se por estado forte aquele que é eficaz na consecução de seus compromissos, que é capaz de mobilizar recursos populares e financeiros para a realização de políticas difíceis. Por essa perspectiva os estados democráticos são considerados hoje mais fortes, mesmo que sejam liberais (MARTIN, 2000).

Neves (2003) afirma que em casos em que os interesses dos poderes executivos são distintos entre si, é posição do autor afirmar que o Legislativo tentará influenciar as decisões do Executivo, de forma direta (participação institucionalizada) ou indireta (pressão política). A primeira pode ser expressa através de comissões temáticas, manipulação orçamentária, ratificação ou não dos tratados assinados e votação de leis domésticas que suportem ou não esse tratados. Discordando da posição do Executivo, os legisladores poderiam buscar maior participação na discussão sobre esses temas e, através da influência direta, minar as ações do Executivo.

Sabendo disso, o Executivo buscaria absorver os interesses dos legisladores, de forma a buscar um consenso que permita uma aprovação dos tratados. De forma bastante simplória, o Executivo sabe de antemão o desejo dos legisladores e a forma

\footnotetext{
${ }^{3}$ Conjunto de soluções em que o negociador acredita que pode ser usado para que se tenha um resultado favorável para si mesmo.

4 "In a multistage collective-choice process, an early-acting individual or group of individuals is said to possess a gatekeeping right if the governing procedures of the body allow the individual or group not to act on specific proposals, and if the certain consequence of such inaction is that an exogenously determined status quo policy remains in effect. A gatekeeping right is therefore a feature of codified rules in the empirical domain and a feature of the game form in the theoretical domain. In contrast, a body or group is said to have gatekeeping power if it has a gatekeeping right and the right produces an outcome that the gatekeeper prefers to the outcome that would have resulted if it did not have a gatekeeping right. Gatekeeping power is therefore a characteristic of a political outcome in a specific empirical domain, and a characteristic of equilibrium play of a game in which a gatekeeping right is postulated to exist. Clearly, then, a gatekeeping right is a necessary condition for gatekeeping power" (CROMBEZ et. al., 2005, p.2).
} 
como esses irão atuar dentro das negociações. Assim, o Executivo já considera os interesses do Legislativo na hora de negociar. Para Putnam, as expectativas de rejeição no nível II (plano doméstico) podem abortar as negociações no nível I (plano internacional) sem qualquer ação formal no nível II (PUTNAM, 1988). Dessa maneira, fica expressa a participação indireta do Legislativo, que acaba influenciando ativamente a posição do Executivo.

\section{Histórico da atuação do Brasil em Operações de Manutenção da Paz}

Segundo informações disponíveis na publicação anual The Military Balance do International Institute for Strategic Studies (IISS) (IISS, 2012), o Brasil dispõe de 328.000 militares no serviço ativo, e de um orçamento de defesa da ordem de 26 milhões de dólares, o $11^{\circ}$ no mundo, correspondentes a 1,66\% de seu Produto Interno Bruto.

À primeira vista, estes dados podem levar à conclusão de que o País, em função do significativo orçamento de defesa e numeroso efetivo militar, deveria participar mais ativamente dos esforços internacionais de paz, como tem sido questionado, principalmente, em encontros bilaterais. No entanto, tal proposição não resiste a uma análise mais detalhada, considerando um universo que inclua outros dados estatísticos nacionais e o desempenho dos demais países do mundo no mesmo âmbito.

Desde 1948, o Brasil participou de mais de 30 operações de manutenção da paz, tendo cedido um total de mais de 17 mil homens. Integrou operações na África (entre outras, no Congo, Angola, Moçambique, Libéria, Uganda, Sudão), na América Central e Caribe (El Salvador, Nicarágua, Guatemala, Haiti), na Ásia (Camboja, Timor-Leste) e na Europa (Chipre, Croácia). Embora tenha enviado militares e policiais em diversos casos, apenas em cinco operações o Brasil cedeu tropas, isto é, unidades militares formadas: Suez (UNEF I), Angola (UNAVEM III), Moçambique (ONUMOZ), TimorLeste (UNTAET/UNMISET) e Haiti (MINUSTAH) (MRE, 2010).

O Brasil é hoje o $12^{\circ}$ maior contribuinte de tropas. Participa de nove missões com 2.258 homens, além de 6 homens em 2 escritórios (UNIOGBIS e UNOWA), totalizando 2.264 (MRE, 2010), estando à frente, por exemplo, dos membros

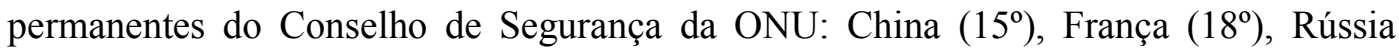
$\left(40^{\circ}\right)$, Reino Unido $\left(43^{\circ}\right)$ e EUA $\left(69^{\circ}\right)$; e de todos os países da União Europeia ${ }^{5}$.

\footnotetext{
${ }^{5}$ Vide em http://www.un.org/en/peacekeeping/contributors/2010/aug10_2.pdf
} 


\section{Limites da atuação do Brasil em Operações de Manutenção da Paz}

A conveniência da participação brasileira em Operações de Manutenção da Paz está condicionada aos interesses nacionais e aos meios que o País pretende dispor para consolidar sua posição no cenário internacional, como, a título de exemplo, para se tornar membro permanente do CSNU.

Nesse contexto, a participação das Forças Armadas brasileiras em missões das Nações Unidas deve ser percebida como um instrumento legítimo na consecução dos interesses nacionais, que proporciona benefícios nos campos político, militar e social, tais como: (1) ampliar a projeção do País no concerto das nações; (2) reiterar o compromisso brasileiro com a defesa da paz; (3) reafirmar a solidariedade brasileira com os países afetados; (4) fortalecer a política externa brasileira; (5) acompanhar a evolução doutrinária e tecnológica de outras forças armadas; (6) manter Forças de Pronto-Emprego; (7) realizar exercícios conjuntos com forças armadas estrangeiras; (8) demonstrar a capacidade de mobilizar tropa em vários cenários; (9) incrementar a participação em ações humanitárias; e (10) permitir a realização de ações sociais junto às comunidades locais (UZIEL, 2010).

As Operações da Manutenção da Paz, além do caráter estratégico, proporcionam o respaldo político necessário à consolidação do Brasil como ator global. Por outro lado, existem outros fatores que devem ser analisados, os quais têm sido apresentados como argumentos para que as Forças Armadas brasileiras não tenham uma participação mais efetiva, com equipamentos e tropas, em missões. Tais fatores, considerados a seguir, podem ser resumidos em quatro áreas: legal, fatores de risco, logística e política.

\section{Aspectos legais}

A incerteza quanto à legitimidade do uso da força na adoção de "medidas provisórias" para a prevenção de conflitos, com base no disposto nos Capítulos VI (que trata da solução pacífica de controvérsias) e VII (que dispõe sobre ações preventivas ou impositivas) da Carta das Nações Unidas (ONU, 1945), levou o Brasil a sustentar sua atuação no âmbito das Operações de Manutenção da Paz em um imaginário Capítulo $\mathrm{VI}^{1} \frac{1}{2}$ da Carta, o qual incorporaria a utilização de recursos militares para fins exclusivamente pacíficos, em missões da ONU, com o consentimento das partes em litígio.

Apesar de as Operações de Manutenção da Paz terem sido, tradicionalmente, associadas ao Cap. VI da Carta da ONU, efetivamente, não há necessidade de o CSNU 
se referir a um capítulo específico da Carta quando autoriza uma operação desta natureza (UZIEL, 2010).

A vinculação das missões de paz em um capítulo em particular da Carta pela ONU pode ser ilusória para efeito de planejamento operacional, treinamento e implementação do mandato. Para avaliar a natureza de cada operação e as capacidades necessárias para apoiá-la, os países contribuintes devem se orientar pelas tarefas atribuídas no mandato, pela concepção da operação e pelas correspondentes regras de engajamento (componente militar) e diretivas sobre o uso da força (componente policial).

No caso brasileiro, as relações internacionais do País têm sido pautadas no fortalecimento dos princípios consagrados pelo Direito Internacional, como a soberania dos Estados, e a prevalência do multilateralismo; e nos princípios estabelecidos no art. $4^{\circ}$ da Constituição Federal (REPÚBLICA FEDERATIVA DO BRASIL, 1988).

\footnotetext{
"Art. 4": A República Federativa do Brasil rege-se nas suas relações internacionais pelos seguintes princípios: I - independência nacional; II - prevalência dos direitos humanos; III autodeterminação dos povos; IV - não-intervenção; V - igualdade entre os Estados; VI defesa da paz; VII - solução pacífica dos conflitos; VIII - repúdio ao terrorismo e ao racismo; IX - cooperação entre os povos para o progresso da humanidade; X - concessão de asilo político” (REPÚBLICA FEDERATIVA DO BRASIL, 1988, Art.4).
}

À luz do princípio que aponta para a "não intervenção", a participação do País em operações que visem à imposição da paz ("Peace Enforcement"), a qual se caracteriza pela intervenção da comunidade internacional em um Estado soberano, como é o caso da maioria das Operações de Manutenção da Paz na África, não encontraria respaldo na carta magna brasileira.

Entretanto, essa argumentação, ao se amparar no princípio da "não intervenção" da Constituição Federal (CF) ou da soberania dos Estados instituída pelo Direito Internacional, não alcança outros aspectos da questão. No que diz respeito aos direitos humanos, a CF faz uma distinção específica ao estabelecer no $\mathrm{n}^{\circ}$ II do mesmo art. $4^{\circ}$ a "prevalência dos direitos humanos" (grifo nosso). Assim sendo, ao confrontar os princípios que regem as relações internacionais do Brasil, devemos, segundo o estabelecido na $\mathrm{CF}$, entender que o País deve priorizar os "direitos humanos" sobre a "não intervenção".

Questiona-se, ainda, o conceito de "intervenção". Segundo o Dicionário Eletrônico Aurélio Buarque de Holanda (FERREIRA, 2010) intervenção é o "ato de um Estado intervir nos negócios internos de outro(s)" ou a "violação da independência dum 
Estado, em virtude da intromissão indébita de outro nos seus negócios internos ou externos". Entretanto, ao se referir a "intervenção humanitária", o mesmo Dicionário esclarece se tratar de "princípio de direito internacional que aceita a intervenção duma comunidade de Estados nos negócios internos ou externos de outro, para evitar morticínios dos próprios nacionais do país sujeito a essa medida".

Assim sendo, segundo o conceito explicitado, uma intervenção coletiva sob os auspícios da ONU no interesse da população sob o risco de morticínio seria considerada "intervenção humanitária" e não uma "intervenção" de um Estado sobre o outro, segundo interesses exclusivos do primeiro. Ou seja, o desencadeamento de uma missão de paz sob a égide da ONU sob a argumentação de prevenir ou conter genocídio, crime de guerra, limpeza étnica ou crimes contra a humanidade não é, necessariamente, uma intervenção, na acepção egoística ou imperialista do termo.

Dessa forma, o apoio brasileiro a uma operação de imposição da paz que tenha sido implementada por razões humanitárias não deve ser descartada, desde que se trate de operação de cunho altruísta e que busque a "prevalência dos direitos humanos" e a "defesa da paz", amparada pela Carta da ONU e legitimada por mandato do seu Conselho de Segurança da ONU, não se caracterizando como intervenção (UZIEL, 2010).

\section{Fatores de Risco}

De qualquer forma, a possibilidade de perdas de pessoal pela exposição a um ambiente insalubre e inseguro, que tem se deteriorado significativamente, inclusive com ataques aos "Peace keepers" e às instalações da ONU, é outro fator que tem sido considerado com especial atenção, ao se analisar a possibilidade de apoio a Operações de Manutenção da Paz. Entretanto, ainda com base nas aspirações internacionais do País, as Forças Armadas, em algum momento, terão de passar a ser empregadas em um ambiente de risco maior do que têm enfrentado nas chamadas missões da ONU, como a MINUSTAH.

\section{Fatores Logísticos}

Qualquer força multinacional terá de agir em cenário complexo, devendo estar adequadamente treinada e equipada, além de ser logisticamente autossustentada em alguns casos. No caso do Brasil, a capacidade logística para atender uma Operação de Paz com emprego de tropa em um continente diferente demanda esforço logístico complexo e dispendioso, o qual tem trazido às Forças Armadas pesados encargos 
operativos e administrativos, cumulativamente com o apoio a missões humanitárias no País e no exterior.

\section{Aspectos Políticos}

A "contribuição para a manutenção da paz e da segurança internacionais" e a “projeção do Brasil no concerto das nações" são objetivos da Defesa Nacional definidos na Política de Defesa Nacional (PDN) (MINISTÉRIO DA DEFESA, 2005) e, em decorrência, a Estratégia Nacional de Defesa (END) estabelece que o Brasil deverá ampliar a participação em operações de paz, sob a égide da ONU ou de organismos multilaterais da região, de acordo com os interesses nacionais expressos em compromissos internacionais. Além disso, estabelece que as Forças Armadas devem ser preparadas para desempenhar responsabilidades crescentes em operações de manutenção da paz (MINISTÉRIO DA DEFESA, 2008).

Para tanto, ainda segundo a END, as Forças Armadas deverão dispor de capacidade de "projeção de poder nas áreas de interesse estratégico", as quais têm sido consideradas como o "entorno estratégico" definido na PDN, para fins de avaliação quanto à participação brasileira em Operações de Paz. A maioria dos países da África, segundo a PDN, não está incluída no entorno estratégico brasileiro, o qual é definido no documento como a América do Sul, a projeção pela fronteira do Atlântico Sul e os países lindeiros da África. Dessa forma, a contribuição com Operações de Paz nos países africanos, exceto aqueles incluídos no citado entorno estratégico, não atenderia aos interesses nacionais.

No entanto, deve-se ter em conta que a mesma PDN destaca que o Brasil atribui prioridade aos países da América do Sul e da África, em especial aos da África Austral e aos de língua portuguesa, estes últimos incluídos na Comunidade dos Países de Língua Portuguesa (CPLP) (MINISTÉRIO DA DEFESA, 2008). Dessa forma, apesar de excluídos do entorno estratégico, os países africanos fazem parte, num contexto amplo, das "áreas de interesse estratégico" nas quais as Forças Armadas devem projetar poder, o que poderá ser efetivado, também, pela participação em missões da ONU.

A prioridade que tem sido atribuída pelo governo brasileiro à África poderá justificar a atuação de forças militares brasileiras no Sudão, apesar daquele país não se encontrar no rol de países africanos com maior atenção da política externa do País, quais sejam, aqueles que estão contidos no entorno estratégico brasileiro, bem como os que fazem parte da Comunidade dos Países de Língua Portuguesa e da Zona de Paz e Cooperação do Atlântico Sul. 


\section{MINUSTAH}

\section{Histórico ${ }^{6}$}

As ações das Nações Unidas no Haiti começaram em 1990, quando a pedido do governo provisório do país a ONU mandou um grupo de observadores para a verificação das eleições gerais vindouras: United Nations Observer Group for the Verification of the Elections in Haiti (ONUVEH sigla em inglês). Em 1991 com o golpe de Estado e deposição do presidente legítimo a situação do país piorou e em resposta uma missão conjunta da ONU e da Organização dos Estados Americanos (OEA) - OAS International Civilian Mission in Haiti (MICIVIH) - foi empregada no Haiti em fevereiro de 1993. Já em setembro de 1993 o CSNU aprovou a primeira operação de manutenção da paz em terras haitianas, a United Nations Mission in Haiti (UNMIH). No entanto, pela falta de cooperação das autoridades militares haitianas a UNMIH não pode ser completamente empregada e seguir o seu mandato (MINUSTAH, 2012).

Em julho de 1994, o CSNU autorizou o emprego de uma tropa internacional de 20 mil homens para o rápido retorno das autoridades legítimas do Haiti, manter o ambiente estável e seguro no país e promover a lei. A força multinacional primeiramente empregada foi seguida por sucessivas Operações de Manutenção da paz de 1994 a 2000, incluindo a UNMIH, que assumiu suas plenas funções em março de 1995, a United Nations Support Mission in Haiti (UNSMIH), a United Nations Transition Mission in Haiti (UNTMIH) e a United Nations Civilian Police Mission in Haiti (MIPONUH) (MINUSTAH, 2012).

Ao longo desse período, houve um número positivo de desenvolvimento, incluindo a restauração de alguns aparatos democráticos com a primeira passagem pacífica de poder entre dois presidentes democraticamente eleitos; o crescimento da sociedade civil organizada e o seu crescente papel no desenvolvimento de uma cultura política baseada em valores democráticos.

Porém, em fevereiro de 2004, um conflito armado eclodiu na cidade de Gonaives e nos dias seguintes se espalhou para outras cidades. Gradualmente, os insurgentes tomaram o controle da parte norte do país. Ao classificar a situação como ameaçadora da paz e segurança internacionais, o CSNU adotou a resolução 1529 (S/RES/1529) autorizando uma força interina, Multinational Interim Force (MIF), e declarou a sua prontidão em estabelecer uma força de estabilização das Nações Unidas

\footnotetext{
${ }^{6}$ Vide em: $<$ http://www.un.org/en/peacekeeping/missions/minustah/background.shtml $>$.
} 
no país para dar continuidade ao processo político pacífico e manter um ambiente seguro e estável.

\section{Mandato ${ }^{7}$}

A Missão das Nações Unidas para a estabilização no Haiti foi aprovada pela resolução 1542 (S/RES/1542) do CSNU de 30 de abril de 2004 para dar apoio ao governo de transição e assegurar um ambiente seguro e estável no país; assistir e monitorar a reestruturação e reforma da Polícia Nacional haitiana; ajudar em programas de desarmamento, desmobilização e reintegração; assistir a restauração e manutenção da lei, segurança pública e ordem no país; proteger os funcionários, instalações e equipamentos das Nações Unidas no país; proteger civis sob ataque físico eminente, suportar os processos constitucionais e políticos locais; assistir, organizar, monitorar e cuidar para que haja eleições municipais, parlamentares e presidenciais; suportar o Governo de Transição e demais instituições nos esforços de promover os direitos humanos dos haitianos; monitorar e reportar a situação dos direitos humanos no país.

A MINUSTAH foi estabelecida por um período inicial de seis meses, com a previsão de renovação por períodos adicionais, e solicitou que a autoridade fosse transferida da Força Multinacional Interina (MIF) para a MINUSTAH em $1^{\circ}$ de junho de 2004.

Nos anos seguintes, o mandato da MINUSTAH, o seu conceito de operações e uso autorizado da força foram ajustados pelo CSNU em diversas ocasiões para se adaptar as mudanças circunstanciais ao longo do tempo, além de se adaptar às necessidades nascentes engendradas pela situação política, socioeconômica e de segurança que assolava o país. Para maiores detalhes, por favor, veja as resoluções 1608 (S/RES/1608), 1702 (S/RES/1702.), 1743 (S/RES/1743), 1780 (S/RES/1780) e 1840 (S/RES/1840) do CSNU (MINUSTAH, 2012).

Não obstante, ao estender o mandato da missão por mais outro ano em 19 de outubro de 2009 pela resolução 1892 (S/RES/1892), o CSNU acreditou à missão a tarefa de dar suporte ao processo político no Haiti através da provisão de assistência material e logística para as eleições antecipadas de 2010. Outrossim, depois do terremoto devastador que atingiu o Haiti em 12 de janeiro de 2010, o Conselho, pela resolução 1908 de 4 de junho de 2010, decidiu aumentar as forças empregadas no Haiti para dar apoio imediato à recuperação e reconstrução do país após o desastre natural.

\footnotetext{
${ }^{7}$ Vide em $<$ http://www.un.org/en/peacekeeping/missions/minustah/mandate.shtml $>$.
} 


\section{Posição do Executivo}

À primeira vista, a decisão brasileira de cooperar com o Haiti parece, segundo Verenhitach, uma decorrência direta de um objetivo geral da politica externa brasileira. (VERENHITACH, 2008). Especialmente dentro do Itamaraty essa versão teve ressonância, defendendo uma politica de fortes princípios, nos quais a resolução pacifica de conflitos ocupa um lugar privilegiado (AGUILAR 2010). Com uma análise mais detida, entretanto, não é difícil perceber um delicado jogo de ideias, “decisões aparentemente inconsistentes, acentuadas ênfases em sutilezas interpretativas que sugerem que a decisão foi mais complexa que o que pareceria a primeira vista" (DINIZ 2005, p. 91).

Analisaremos aqui a posição do poder Executivo como sendo de interesse fixo: a aprovação pelo Congresso brasileiro do envio de tropas para a MINUSTAH. Posição que dependeu de um novo posicionamento de política externa, adotado pelo Presidente Lula. O que nos leva a considerar que a atual decisão de intervir no Haiti foi tomada sob uma forte participação presidencial (VERENHITACH 2008, p. 56). Alessandra Falcão Preto esclarece esse ponto:

O presidente pode receber conselhos de especialista de politica externa, mas suas escolhas em decisões de política externa são em última análise formadas por: suas próprias preferencias, que podem ter origem em experiências anteriores no Executivo; pelo grau em que ele se julga conhecedor e competente em questões de política externa e segurança nacional; e por sua personalidade (PRETO, 2006, p. 75-76).

Como disse o Presidente Luís Inácio Lula da Silva, em seu discurso na 59a Assembleia Geral da ONU, em 21 de setembro de 2004:

Foi assim que atendemos, o Brasil e outros países da América Latina, a convocação da ONU para contribuir na estabilização do Haiti. Quem defende novos paradigmas nas relações internacionais, não poderia se omitir diante de uma situação concreta (LULA DA SILVA, 2004, p. 1).

Mesmo realizada segundo os canais pertinentes, a decisão hierárquica, de cima para baixo (“top-down”) (VERENHITACH, 2008) despertou uma série de protestos dentro e fora do governo por parte de diversos intelectuais, legisladores, líderes sindicais e parlamentares (IOAKIMEDES, 2006). A Comissão de Relações Exteriores e de Defesa Nacional se declarou frontalmente contrária ao envio de tropas brasileiras ao Haiti. A discussão sobre a autorização do envio de 1200 soldados teve um alto tom de 
oposição. De maneira geral, a discussão foi dominada pela oposição do governo (SARMIENTO, 2010).

\section{Debate no Legislativo}

O sistema político do Brasil pode ser descrito como "presidencialismo de coalizão", ou seja, um presidencialismo multipartidarista caracterizado por um presidente institucionalmente capaz de conformar maiorias no congresso, garantindo estabilidade e governabilidade ao sistema político (FIGUEIREDO ET LIMONGI, 1999). A maioria legislativa conformada pelo presidente eleito compõe a coalizão governista, sustentada em grande medida pelos amplos poderes legislativos e de agenda do presidente e pela nomeação de cargos executivos. Desta forma, o presidente induz os parlamentares à cooperação, costumando-se observar elevados índices de disciplina partidária entre os partidos que conformam a coalizão governista (FELIU ET MIRANDA, 2011).

Com 118 votos contra a proposta, 266 a favor e uma abstenção, a medida que autorizava o Brasil a participar da Operação de Paz no Haiti só foi aprovada naquela data devido a um acordo entre as lideranças da oposição e governo, para que não houvesse verificação dos votos (CÂMARA DOS DEPUTADOS, 2004). O debate que antecedeu a votação, ocorrido em 13 de maio de 2004, girou em torno da política externa do governo como um todo, concentrando-se em aspectos como o papel de liderança a ser assumido no continente, as contradições entre a utilização das forças armadas dentro e fora do país e a própria atribuição do Congresso no envio de tropas ao exterior (FELIU ET MIRANDA, 2011).

Segundo a lei de remessas de tropas para o exterior, aprovada em 1956, o envio de contingentes militares para o estrangeiro só poderia ser feito mediante aprovação do Congresso, nos termos da Constituição (REPÚBLICA FEDERATIVA DO BRASIL, 1956). No entanto, o fato das tropas destacadas para a missão já terem sido transferidas do Rio Grande do Sul para o Rio de Janeiro e começado as preparações para a viagem antes da autorização do Congresso - com ampla cobertura da mídia - causou grande desconforto em diversos legisladores (FELIU ET MIRANDA, 2011). O deputado federal Fernando Gabeira (sem partido - RJ) afirmou que "a catástrofe de o Congresso Nacional perder suas prerrogativas, e perder por vontade própria" como "uma das situações mais terríveis que podem acontecer nesta Legislatura" (CÂMARA DOS DEPUTADOS, 2004). 
GRÁFICO 1: Votação sobre o envio de tropas ao Haiti no Brasil

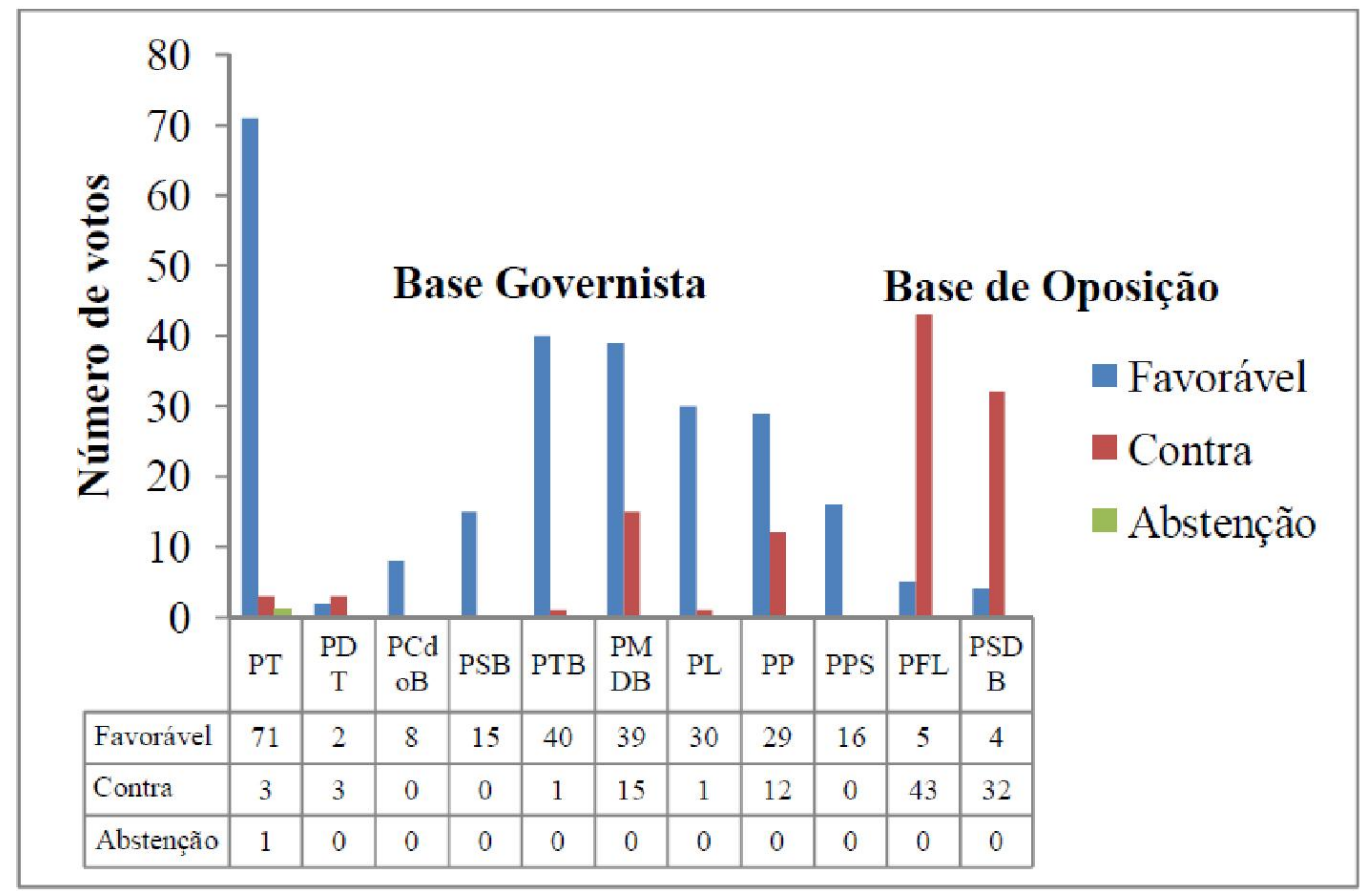

Fonte: (FELIU ET MIRANDA, 2011, p.326) a partir de dados de http://www2.camara.gov.br

\section{A oposição}

Alguns congressistas contrários ao envio de tropas argumentaram que a participação brasileira na MINUSTAH constituía mero apoio à política intervencionista norte-americana na região caribenha e que o envio de tropas serviria para corroborar um golpe de Estado abertamente apoiado pelos Estados Unidos (CÂMARA DOS DEPUTADOS, 2004).

Uma missão nos moldes apresentados representaria clara ingerência nos assuntos internos haitianos, sendo muito mais sensato o envio de ajuda humanitária ao Haiti no lugar de tropas. O discurso do deputado Roberto Freire (PPS-PE) resume bem essas posições: "O Haiti tem suas forças políticas. Tem um quadro político caótico, mas eles têm de resolver a situação. Se possível, enviemos Parlamentares ou instituições humanitárias para prestar apoio efetivo. (...) Não podemos, porém, subordinar-nos a uma política que amanhã, seja por distúrbios internos, seja por problemas de infraestrutura, seja porque interessa aos Estados Unidos pode voltar-se contra nós (...). Estamos equivocando-nos" (CÂMARA DOS DEPUTADOS, 2004).

Foi levantado pela oposição que seria para o País uma aparente contradição enviar tropas para o exterior, em face de situações de extrema violência dentro do território nacional. O deputado Luiz Carlos Hauly (PSDB-PR) questionou a ausência 
das forças armadas nas áreas de conflito do Rio de Janeiro: "se é possível fazer segurança em outros países, por que não empregar metade do efetivo das Forças Armadas Brasileiras para fazer o mesmo trabalho no Brasil, sobretudo em situações graves como a que vemos no Rio de Janeiro?” (CÂMARA DOS DEPUTADOS, 2004).

De um modo geral, a oposição faz frente aos princípios norteadores da política externa do governo, do qual a MINUSTAH é um dos principais produtos (FELIU ET MIRANDA, 2011, p.326). Questionam a verdadeira essência dos motivos brasileiros, tendo em vista a campanha aberta pela obtenção de um assento permanente para o Brasil no Conselho de Segurança da ONU, classificando como "lamentável" o envio de soldado em troca do assento.

\section{Bancada governista}

Para os deputados favoráveis ao projeto, o envio de tropas brasileiras ao Haiti representaria, ao mesmo tempo, uma continuidade na tradição brasileira em participação de missões de paz e um passo adiante na construção da liderança brasileira. Reforçando essa posição, o deputado Renildo Calheiros (PCdoB-PE) declara: "o Brasil viria exatamente no sentido de confirmar a política externa brasileira de defesa da paz internacional e da autodeterminação dos povos. Além disso, reafirmaria a postura do Brasil de procurar ser ouvido internacionalmente e de querer levar sua posição aos fóruns internacionais para ajudar no esforço democrático" (CÂMARA DOS DEPUTADOS, 2004).

Em consonância com a política externa realizada pelo governo Lula, estes deputados defendiam a legitimidade da busca brasileira por um assento permanente no Conselho de Segurança, e a possibilidade de liderança da MINUSTAH como uma alavanca para tal objetivo. Para o deputado Arlindo Chinaglia (PT-SP), a participação seria fundamental para além dos interesses estratégicos brasileiros: “[o] Brasil amplia influência e consolida-se como liderança mundial. Isso interessa não ao governo, mas ao Brasil. É um esforço de governos sucessivos" (Câmara dos Deputados, 2004). O engajamento brasileiro na missão não só correspondia à defesa dos direitos humanos prevista constitucionalmente como também respondia a um esforço internacional comandado pelo único órgão com legitimidade para tal incumbência, a ONU - que mesmo em meio a uma crise de credibilidade, ainda era a melhor opção.

Por fim, o deputado Paulo Delgado (PT-MG) rebate o argumento de que o Brasil deveria se concentrar mais em situações de violência e pobreza internas, afirmando que a solidariedade internacional não implica necessariamente indiferença em relação à 
política doméstica e que o próprio Brasil se beneficiara dessa solidariedade em diversas ocasiões (Câmara dos Deputados, 2004).

\section{Conclusão}

O principal argumento desenvolvido no texto tem como alicerce a forte diplomacia presidencial e pressão do poder Executivo para a aceitação da participação da MINUSTAH pelo Congresso Nacional do Brasil. A qual pode ser constatada pelo conceito de "presidencialismo de coalisão" por meio dos votos dos deputados.

Por meio da análise dos debates travados no plenário da Câmara, identificamos o conteúdo substantivo que pauta a polarização entre as coalizões de governo e oposição. De um modo geral, entre os discursos contrários, observou-se a ênfase no envio de uma ajuda humanitária ao invés de tropas, críticas aos gastos da missão e o risco de uma missão fracassada, dada as condições do Haiti, afetar negativamente a imagem dos países em questão.

Já entre os discursos favoráveis foi possível analisar um comprometimento com a política governista de continuidade na inovação e consecução dos paradigmas doutrinários que guiam a diplomacia brasileira, com uma ênfase no enaltecimento de um papel assertivo e independente na manutenção da ordem internacional, especialmente no continente, além das pretensões por um assento permanente no CSNU.

O presente trabalho tentou, assim, cristalizar e clarificar a dinâmica específica do aceite de Missões de Paz pelo Brasil no âmbito do poder legislativo e como as análises que privilegiam a incorporação da arena doméstica no processo decisório da política externa ainda precisam ser amplamente estudadas.

\section{Referências Bibliográficas}

AGUILAR, Sérgio Luiz Cruz. Uma Cultura Brasileira Em Operações de Paz. Associação Brasileira de Estudos de Defesa. Disponível em: <www.abed-defesa.org/>. Acessado no dia 07 de junho de 2012.

AMORIM, Celso. A diplomacia multilateral do Brasil: Um tributo a Rui Barbosa. In II Conferência Nacional de Política Externa e Política Internacional: O Brasil e o Mundo que vem aí. Brasília: Fundação Alexandre Gusmão, p. 5-21, 2007.

BULL, Hedley. The Anarchical Society: A Study of Order in World Politics. London: Macmillan. 1977. 
CÂMARA DOS DEPUTADOS. Diário da Câmara dos Deputados (13.05.2004). Brasília. Imprensa Oficial do Governo Brasileiro, 2004.

CONSELHO DE SEGURANÇA DA ONU. (2004) Resolução 1529, 29 de fevereiro, S/RES/1529.

. (2004), Resolução 1542, 30 de abril, S/RES/1542.

(2005). Resolução 1608, 22 de junho, S/RES/1608.

(2006). Resoluç ão 1702, 15 de agosto, S/RES/1702.

. (2007). Resolução 1743, 15 de fevereiro, S/RES/1743.

(2007). Resolução 1780, 15 de outubro, S/RES/1780.

(2008), Resolução 1840, 14 de outubro, S/RES/1580.

CROMBEZ, C. GROSECLOSE, T. KREHBIEL, K. Gatekeeping. University of Leuven, September 28, 2005. Disponível em: http://www.sscnet.ucla.edu/polisci/faculty/groseclose/Working.Papers/JoP-

Gatekeeping.pdf. Acesso em: 11 abril 2015

DINIZ, Eugenio. O Brasil e a MINUSTAH. Security and Defense Studies Review, Washington D.C., v. 5, n. 1, p. 90-108, 2005.

FELIU, Pedro. MIRANDA, Rosana. Congresso Nacional e Política Externa. O caso do envio de tropas ao Haiti: Argentina, Brasil e Chile. In: Revista Política Hoje, Vol. 342 20, n. 1, 2011.

FERREIRA, A.B.H. Aurélio Século XXI: o dicionário da Língua Portuguesa. 5. Ed. Ver. E ampl. Rio de Janeiro: Nova Fronteira. 2010.

FIGUEIREDO, Argelina e LIMONGI, Fernando. (1999), Executivo e Legislativo na nova ordem constitucional. Rio de Janeiro, Editora FGV.

FONTOURA, P.R.C.T. O Brasil e as Operações de Manutenção da Paz das Nações Unidas. Brasília. FUNAG, 1999.

HILL, Christopher. The Changing Politics of Foreign Policy. Hampshire. New York. Palgrave Macmillan. 2003.

HIRST, Mônica e LIMA, Maria Regina. Contexto Internacional, Democracia e Política Externa. In: Política Externa. 2002. v.11. n.2. p.78-98

INTERNATIONAL INSTITUTE FOR STRATEGIC STUDIES. The Military Balance 2012. 2012.

IOAKIMEDES, Anna. Is Brazil Selling Out Haiti for Its Own Gain? Disponível em: $<$ http://www.coha.org/the-brazilian-military-is-back-as-it-fleshes-out-its-weaponry-andstrategies/>. Acessado em 7 de junho de 2012

LIMA, Maria Regina Soares de. Ejes Analíticos y Conflicto de Paradigmas em la Política Exterior Brasileña. In: América Latina Internacional, 1994, v.1. n.2, p.27-40.

LULA DA SILVA, Luiz Inácio. Discurso do Presidente Lula na 59 ${ }^{\text {a }}$ Assembleia Geral da ONU. Disponível em: <http://www.escoladegoverno.org.br/biblioteca/132discurso-lula-59-assembleia-onu>. Acessado no dia 7 de junho de 2012.

MARTIN, Lisa. Democratic Commitments: Legislatures and International Cooperation. Princeton. Princeton University Press. 2000. 
MELLO E SILVA, Alexandra de. Idéias e política externa: a atuação brasileira na Liga das Nações e na ONU. In: Revista Brasileira de Política Internacional, v. 41 (2): 139$158,1998$.

MINISTÉRIO DA DEFESA. Política de Defesa Nacional. Brasília. 2005

. Estratégia Nacional de Defesa. Brasília. 2008.

MINISTÉRIO DAS RELAÇÕES EXTERIORES. Balanço de Política Externa: 20032010. 2010. Disponível em: < http://www.itamaraty.gov.br/temas/balanco-de-politicaexterna-2003-2010/listagem view_ordem pasta?b_start:int $=0 \&-C=>$ Acesso em 25 jun. 2012

MINUSTAH. Mission des Nations Unies pour la stabilisation en Haïti. Site Oficial. 2012. Disponível em: http://minustah.org/?page id=7858. Acesso em 26/06/2012.

NEVES, Antônio Augusto de Castro. O Papel do Legislativo nas Negociações do Mercosul e da Alca. In: Cena Internacional. 2003. Ano.5. n.3.

ORGANIZAÇÃO DAS NAÇÕES UNIDAS. Carta das Nações Unidas: Secretaria das Nações Unidas, 1945.

PRETO, Alessandra Falcão. O Conceito de Diplomacia Presidencial: O Papel da Presidencia da República na Formulação de Política Externa. Dissertação (Mestrado em Ciência Política) - Departamento de Ciência Política da Faculdade de Filosofia, Letras e Ciências Humanas, Universidade de São Paulo, 2006.

PUTNAM, Robert. Diplomacy and Domestic Politics: The Logic of Two-Level Games. In: International Organization. v. 42 (Summer 1988). pp. 427-460.

REPÚBLICA FEDERATIVA DO BRASIL. (1956), Remessa de tropas brasileiras para o exterior, Lei ${ }^{\circ} 2.953 / 56$ de 17 de novembro de 1956.

. (1988). Constituição Federal. 1988

. (1994). Fixa as condições para a participação do Brasil em operações patrocinadas por organismos internacionais intergovernamentais, Projeto de Lei $\mathrm{n}^{\circ} 4.380 / 94$ de 23 de fevereiro de 1994.

SARMIENTO, Luis Capelo. O Brasil e a MINUSTAH: As motivações e as Consequências de Uma Operação pelo Brasil. Fortaleza, Universidade Federal do Ceará, 2010.

TSEBELIS, G. The Power of the European Parliament as a Conditional Agenda Setter. The American Political Science Review, Vol. 88, No. 1 (Mar., 1994), pp. 128-142. Disponível em: http://sitemaker.umich.edu/tsebelis/files/power_of the european_parliament 1994 aps r.pdf Acesso em: 11 abril 2015

UZIEL, Eduardo. O Conselho de Segurança e a Inserção do Brasil no Mecanismo de Segurança Coletiva das Nações Unidas. Brasília. FUNAG. 2010.

VERENHITACH, Gabriela Daou. A Minustah e a Política Externa Brasileira: Motivações e Consequências. Dissertação (Mestrado em Integração Latino-americana) Programa de Pós-Graduação em Integração Latino-americana, UFSM. Santa Maria: UFSM, 2008. 